\title{
To Be or Not To Be: Exploring the Career Choices of Secondary and Senior Secondary School Students of Delhi
}

\author{
Sumbul Abid
}

\begin{abstract}
The term career can be defined as the sequence of interaction of individuals with society, education and organisations throughout their lifespan. The aim of the present study was to study various possible determinants influencing the career choices \& path of the Secondary \& Senior Secondary School Students. The data was collected from 22 Students (Males \& Females) of 1 Private and 1 Government School each belonging to the Age group of 14-16, studying in $10^{\text {th }}$ and $11^{\text {th }}$ Grade in Delhi. A semi-structured Interview schedule was formulated and necessary information was further retrieved pertaining to the information of academic background of the participants, preferred courses of the participants which they wish to pursue and the factors influencing their career decisions such as limited choices of the course in the college, social prestige of the desired career, socio-economic factors or any other factors. The data collected from the semi-structured interview was summarized, analyzed and interpreted using the descriptive statistical tools such as frequency distribution and was also qualitatively analyzed. The present study helped us to probe various aspects of Career choices \& to become aware of career decision making process of the students. No major difference was found in the factors affecting the students of private school as compared to government school.
\end{abstract}

Keywords: Career, Career Decisions, Semi Structured interview

\section{INTRODUCTION}

A career can be defined as a pattern of work experiences comprising the entire life span of a person and which is generally seen with regard to a number of phases or stages reflecting the transition from one stage of life to the next (Weinert, 2001). Similarly, Collin (1998) explains that the term career arises from the interaction of individuals with organisations and society. This interaction, as Savickas (2009) proposes, is no longer merely just a sequence of jobs but is now a story that working people build about themselves. The term "career" can therefore be defined as the sequence of interaction of individuals with society, education and organisations throughout their lifespan, if we take a developmental approach. It is necessary, however, to emphasise that the majority of the responsibility now rests on the individual for their own career progression, which requires sustained employability (Beukes, 2009; Herr et al., 2004).

Students all over the world are usually faced with the task of career decision making. The choice of careers, subjects, and courses of study in schools and of subsequent paths to follow is always difficult problems facing prospective undergraduates. Often, choosing the right subject combination leading to the right profession can make the difference between enjoying and detesting the career in future. Dedicating oneself to career choices that are unattainable leads to frustration. Each individual undertaking the process is influenced by many factors, including the context in which they live, their personal aptitudes, and educational attainment (Bandura, et al. 2001). General agreement exists on the position that to be able to successfully cope with the myriad challenges that await them in the world of work (e.g., job changes, part-time and temporary contract work), young people need to learn and be able to effectively use self-directing agentic skills (Betz \& Hackett, 1987). Constructs such as career adaptability (Savickas, 2013), career self-management (Lent \& Brown, 2013), and self-constructed career identities (Flum \& Blustein, 2000) point to the conclusion that young people need to take charge of their lives and be the "authors of their own becoming" (Flum\&Blustein, 2000, p. 392). Agency provides individuals an adaptive advantage to be able to engage in the present and move toward the future in coherent and purposive ways to realize personally valued short- and long-term goals.

In one of his studies, Sen (1995) recognises the differences between individuals in terms of their ability to make use of the resources they can access. He argues that even when persons are provided with equal resources it does not necessarily mean that they have access to equal opportunities (Saito, 2003). For instance, a disabled person will usually require additional resources to be able to have equal opportunities to a person without disability.

Not only are there differences between individuals but there can be differences in resources as well. School education is one such case in point. Unterhalter (2003), for example, suggests that education and schooling should be distinguished from each other. In her conceptualisation, education is an abstract good, a concept that is operationalised through the process of 'schooling'. Differences in this process and in the quality 
To Be or Not To Be: Exploring the Career Choices of Secondary and Senior Secondary School ..

of schooling can lead to differences in learning outcomes. Therefore, while 'education' might play a significant role in capability enhancement (Walker, 2005), schooling, as a process, can in some cases provide a poor quality of education. Lower quality schooling can even limit a person's capability by, for example, discouraging students from desiring things that are perceived as unattainable or by limiting their exposure to key information and advice. Lower quality schooling can also affect students' academic achievements over time, leading to a loss of confidence and difficulties accessing the academic school curriculum. Such difficulties may eventually impact how students perceive their suitability for careers requiring degree qualifications, negatively affecting their future career aspirations. The ability to envision and enact a viable career choice is thus a developmental outcome, one that is influenced by personal characteristics and background, as well as educational experiences. Student career choice 'capability' should therefore be analysed by placing 'equal emphasis on the interaction between individual students and the nature and quality of the education they receive' (Galliott\& Graham, 2014).

Chelsi (2006) described Erikson's eight stages of psychosocial development and explained that in the adolescence period, if the adolescent does not gain a strong sense of self, she/he will experience some identity confusion. It is the period when the child learns identity or identity diffusion. The individual who has a high self concept of himself, with the appropriate career guidance, has confidence in making good career decision. The converse is the case with one who has a low self concept.

According to the theory of vocational development by Supeer (2005), the student should first become aware of the need for a career. So students need a wise choice in decision making. Bautista (1997) stated that at this stage, a student must take important and vita decision in the selection of a career which will determine his future success.

Thus, in order get into the mindset of becoming proactive with the career decisions, it becomes essential for schools and career teachers to serve as the agents to substantiate changes and the intended paradigm shift. It is therefore obviously important to support the adolescents the secondary school students in their career choice, to ensure they make comfortable career decisions, which is a major decision to make prior to admission in to the formal higher educational institutions.

\section{RELATED LITERATURE}

The review of related literature covered the study of the career preferences of the respondents. The related literature provides a fundamental background for the discussions and considerations in finding the present study. Ferry (2006) asserts that adolescent occupational choice is influenced by many factors, including the context, personal aptitudes, and educational attainment. He contends further that whether college - bound or work - bound, meeting the challenge of this developmental milestone is critical in adolescents' lives. Students all over the world usually faced with the task of career decision making. The choice of careers, subjects, and courses of study in schools and of subsequent paths to follow is always difficult problems facing prospective undergraduates.

Encarta (2005) stated that Colleges and universities provide necessary training for individuals wishing to enter professional careers. They also strive to develop students' creativity, insight and analytical skills. By acquainting students with complex ideas in an intellectually stimulating environment, colleges and universities can provide unique opportunities for personal enrichment while also preparing students for future careers.

In one of the studies, Goffee and Jones(2000) pointed out that since private life is gaining importance ;professional careers are profoundly shaped by family, the career and life choices of his/her partner, and by children and elders who need care and time. In addition, an individual's career cannot be understood outside the person's relationship with one or more other persons because the division between work life and personal life is much more blurred these days.

Similarly, a study done by Cooper and Perkinson (2007) indicated that there are numerous and wide range of characteristics that influence students' choice of course and university. For instance, Sociologists emphasize that parents have strong influence on their children's choice of career. They stressed that in some cases, children inherit their fathers' occupations. Children choose occupations within the range acceptable to parental values, expectations and social status (Friesen, 1981). This might not be in the interest of the child and the society, since he or she might make an unsatisfying choice. Holland's Career Typology in 1959 noted that individuals are attracted to a particular occupation that meets their personal needs and provides them satisfaction (Savickas\&Lent , 1994 ; Stitt- Gohes, 1997). To corroborate this theory, the result of a study by Agarwala (2008) showed that skills, competencies and abilities were the important factors that influenced career choice of management students in India. There is also the gender bias, which is the strongest criticism of Holland's theory.

It has been observed that there are male dominated and female dominated occupations. Gender bias might be due to societal expectations of male and female sex roles. Gottfredson (2005) argued that during adolescence, students have achieved an adult- level understanding of sex type. He added that adolescents start to eliminate occupational choices based on sex types and prestige level. Hence, female students might avoid 
To Be or Not To Be: Exploring the Career Choices of Secondary and Senior Secondary School ..

choosing occupations that are generally perceived to be masculine e.g miner. This could play down the interest and abilities of an individual, which ought to be significant factors for consideration in career choice. Related to this is the self-concept theory of Donald E. Super in 1963. He theorized how a person consciously or unconsciously defines himself in terms of self-concept, and the definition influences his choice of career (Lacey\&McNoldy, 2008). In line with this, Gottfredson (2005) stated that by age 13 to 14, adolescents have developed two cognitive competencies related to career development: self-concept and perceptions about occupations. Thus adolescents' choice of career might be influenced by their self-concept. Hence Combs (1982) as cited by Ornstein and Hukins (2004) noted the Phenomenologist's position that: what we do, even to what extent we learn, is determined by our concepts of ourselves.

It has also been found that Career choice is not unbridled. Rather, career choices are often constrained by sociocultural factors (Swanson and Gore, 2000), individual factors, personal and cultural values, significant relationships, and structural factors such as barriers faced by women in certain careers such as management. Most career choice research has focused on predicting career choice behaviors based on personality or demographic variables ( Özbilgin et al.2005). Studies attempting to identify career choice influencing factors have focused largely on individuals' aptitudes, interests, opportunities, etc.

\section{RATIONALE OF THE STUDY}

The importance of career choice is a growing concern to the educators as well as the students. Most of the studies done on the factors influencing the career choices of the students had only dealt with the private school students and undermined the fact that there could be a possibility that the factors affecting the career choices could differ between the students studying in private schools as compared to the government school. Lack of studies stating the differences in the career choices and factors affecting the same among private and government schools gave the impetus to the idea of exploring the differences between the two set of schools. Also, the research scholar has worked as a career counsellor for about 3 years, guiding the government school students of Jharkhand, Bihar and adjoining area, which becomes the guiding source for the researcher to explore the same in the Students of Delhi-NCR.

\section{Research Objective}

To explore various possible factors determining the career choices and path of the Secondary \& Senior Secondary School Students.

\section{Research Design}

In the present study, Descriptive research design has been used. A descriptive research can be explained as a statement of affairs as they are at present with the researcher having no control over variable. Moreover, descriptive research may be characterized as simply the attempt to determine, describe or identify what is, while analytical research attempts to establish why it is that way or how it came to be. In its essence, descriptive studies are used to describe various aspects of the phenomenon. In its popular format, descriptive research is used to describe characteristics and/or behavior of sample population. Moreover, mixed method design will also be considered, making the design a combination of qualitative and quantitative analysis of the study. A mixed methods approach is one in which the researcher tends to base knowledge claims on pragmatic grounds. It employs strategies of inquiry that involve collecting data either simultaneously or sequentially to best understand research problems.

\section{Sample}

The data was collected from 22 Students (Males \&Females) of 1 Private and 1 Government School each belonging to the Age group of 14-16, studying in $10^{\text {th }}$ and $11^{\text {th }}$ Grade in Delhi. The purpose of doing this research in Delhi was that there are more than 4979 schools in Delhi (Aided and unaided by MCD, NDMC, DSW) which are recognised by the Delhi Government (As per the data recorded on the website of Directorate of Education). Apart from this, there are many schools which are not recognised by the government too. Additionally, Delhi, as a capital of the country and one of the metro cities, has a number of private and international school chains also. Delhi being an Hub and national Educational Capital attracts students from almost all northern, central, eastern states and also other parts of the country as well as from a number of other countries.

Rationale behind taking the $10^{\text {th }}$ grade students as a sample of the study was that this is the stage when the students are required to make the necessary choices with respect to the streams in which they would like to be in and the subjects for class $11^{\text {th }}$ are opted in this phase. Their probable future academic orientation is reflected in the choices they make for a particular stream (Science/Commerce/Arts), for which they take the decision in class $10^{\text {th }}$ only. Therefore, the factors affecting their career choices can be probed in the initiation phase of selecting a particular career direction in class $10^{\text {th }}$ only. Also, students who wish to pursue careers such 
as engineering, medical, IAS, etc; they tend to join coaching classes for the same as soon as they enter the $11^{\text {th }}$ grade, which also reflect their career goals and choices, which can be further, explored and probed.

The sample size varied from the earlier plan, depending upon availability of the sample and other considerations.

\section{Tool used}

A semi-structured Interview schedule was formulated and necessary information was further retrieved pertaining to the information of academic background of the participants, preferred courses of the participants which they wish to pursue and the factors influencing their career decisions such as limited choices of the course in the college, social prestige of the desired career, socio-economic factors or any other factors.

Semi-structured interviews are conducted with a fairly open framework which allow for focused, conversational, two-way communication. They can be used both to give and receive information. According to Bernard (1988), it is best used when a researcher won't get more than one chance to interview someone and when you will be sending several interviewers out into the field to collect data. Focus group discussion was also used as a tool for data collection as it facilitated more sharing of information from students.

\section{Data analysis and report writing}

The data collected from the semi-structured interview was summarized, analyzed and interpreted using the descriptive statistical tools such as frequency distribution and was also qualitatively analyzed.

\section{Profile of the Respondents}

A total of 22 students of class $10^{\text {th }} \& 11^{\text {th }}$ from one government \& one private School, served as the respondents of this study. Most of the respondent belonged to private school (16 out of 22) situated in East Delhi. Other respondents were from a government school situated in central Delhi.

Also, as per the sex distribution, 11 were females \& 11 were male respondents. In private school, 3 females belonged to class $11^{\text {th }}$ and 2 from class $10^{\text {th }}$. In the government school, all the 6 respondents were females only. Most of the students interviewed in private schools were the only child of their parents whereas students interviewed in government school, most of them were the youngest child in their families. Parents of most of the respondents of private school are well settled and are into the jobs such as banking, teaching, defence, engineering, medical etc. Mothers of all the respondents excluding 2 of them are working. Whereas the mothers of the respondent of government school are homemakers, one of them is also giving part time tuitions to primary school students. The income bracket of respondent's parents was reported to be low for government school students as compared to the private schools.

The academic background of the students of private school is quite good. The average CGPA is 9 for private school respondents in their recent/previous class. Whereas the respondents of the government school reported that they have performed very well in their previous exams but could not remember the exact percentage. One of them reported $85 \%$ in her previous exams in class $10^{\text {th }}$.

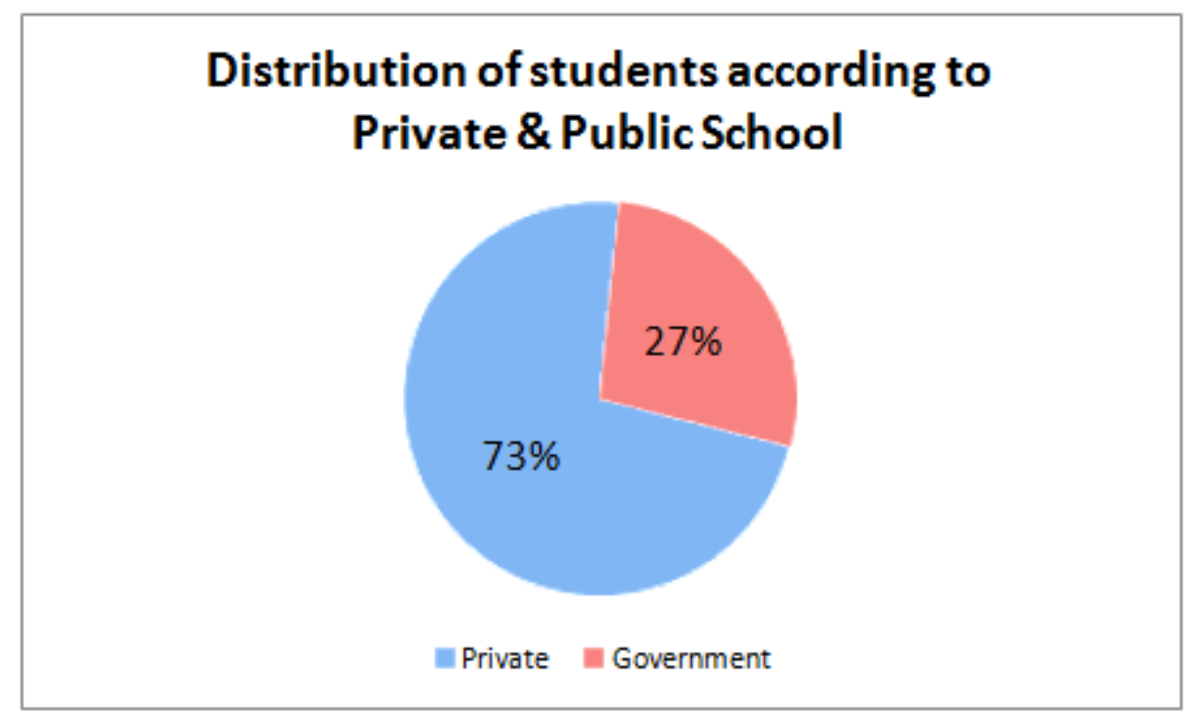

Diagram 1: distribution of students according to Private and Public Schools 


\section{DISCUSSION}

Among the factors affecting career choices of the respondents of both the schools, peer pressure as a social influence was not reported as having an influence on the career decision making career choices of the students. Students of both the sectors of school disagreed on the direct influence of this factor. Most of the private school students disagreed that the accessibility of the school/college from the residence does not influence the career decision and career choices of the students. But the same factor is of importance for respondents of government school.

Table 1: Frequency distribution of the responses given by the respondents

\begin{tabular}{|l|c|c|c|c|}
\cline { 2 - 5 } \multicolumn{1}{l|}{} & \multicolumn{3}{c|}{ Private School } \\
\hline Factors & Strongly Disagree & Disagree & Agree & Strongly Agree \\
\hline There is no available / limited choice of & 1 & 6 & 7 & 2 \\
course in the college & 1 & 6 & 7 & 2 \\
Scholarship not offered in the priority & 1 & 3 & 6 & 6 \\
courses & 1 & 1 & 7 & 7 \\
Social prestige of the desired career & 3 & 9 & 3 & 1 \\
Employability rates of the course after & 0 & 4 & 10 & 2 \\
finishing college & 0 & 5 & 10 & 1 \\
Social influences (peers pressure) & 4 & 7 & 5 & 0 \\
Social Influences (Family) & & & & \\
Can't afford the desired course & 1 & 5 & 7 & 3 \\
The school is accessible to your residence & & & & \\
Low interest or perceived low mental ability & & & \\
for the student to enroll into the desired & & & \\
course & & & \\
\hline
\end{tabular}

\begin{tabular}{|c|c|c|c|}
\hline \multicolumn{4}{|c|}{ Govt School } \\
\hline Strongly Disagree & Disagree & Agree & Strongly Agree \\
\hline 0 & 0 & 5 & 1 \\
0 & 0 & 1 & 5 \\
1 & 2 & 3 & 0 \\
0 & 1 & 2 & 3 \\
0 & 4 & 2 & 0 \\
0 & 0 & 2 & 4 \\
0 & 0 & 2 & 4 \\
1 & 2 & 3 & 0 \\
1 & 3 & 1 & 1 \\
& & & \\
\hline
\end{tabular}

Almost half of the respondents from government school disagreed that low interest or perceived low mental ability for the students to enroll into the desired course affect the career choices of the students. All of them agree that the factors that scholarship and subsidies offered in priority courses, social prestige of the desired career, employability rates of the course after finishing college, social influence of family, affordabilityof the desired course, and low interest on low mental ability for the student to enrol the desired course (only public school students) are the factors that might affect their career choice.

Among the government school respondents, all of them agreed that the problems they encountered or may encounter in future which have affected and might affect their career choice are "financially unable to support the desired course; far residency and accessibility to the desired school, and scholarship offered are limited". The employability scope after college is also of great concern for students of both sectors as reported by them. As per the responses given by the students, especially of private school, they reported that the occupation of their parents has also influenced them to opt for a particular career path or their future career related decisions. Most of the respondent's parents are placed in reputed fields such as medical field, engineering, banking sector, teaching, defence etc. They have reported to be influenced by these factors as well. According to them, they have become more ambitious due to this.

The respondents from government school did not report any such factor. All the respondents from government schools reported that their mothers are homemaker and fathers are doing a job in which they could only fetch minimal amount to feed the family. Only one out of 6 government school respondents reported that her mother is a teacher.

It was observed throughout the process of data collection that the private school students were more willing to participate in the research than the government school students. When the respondents of private school were asked to talk about their favourite subjects \& their preferred course choice in graduation, most of the student's subject of interest \& their course preference in college correlated and matched. When they were asked about what course they would enroll in if they do not get in to the course of their choice, they reported allied subjects of their first preference. All the private school students wanted to go for the courses of their interest. Although, in the interview \& FGD, they also shared the influence of their families and how their interests are not aligned with the ideas \& decisions of parents. When asked about the role models, for most of them, it was their parents or either of them who served as a role model. Most of the respondents saw their parents as a role model as well as the guiding force behind their career decision making process $\&$ choices as well. This got correlated when they were asked to rate the factors affecting the career choices on a 4 point rating scale. Two of them named the famous personality like Sachin Tendulkar to be their role models and guiding force behind their careers. Factors such as salary structure after studies, working hours, motivation and negative factors such as corruption were also reported as having major influence on career decisions when asked for other factors affecting the career choices of the students. 
Students from both the school sectors reported that scholarships are of great help to the students who are financially less sound and it helps them to reach their goals and aspirations easily. The importance of assistance in the form of counselling was supported only by private school students. Government school students were not aware about the counselling services of their respective school therefore they did not say much about this.

Respondents from both the school actually reported the importance of guidance for career preferences but they were more confused about the process. For example one student reported- "I know what I want to do in future but i am not aware about the colleges which offer my preferred course \&I don't know how my parents will react to my choice of course. They want me to do something related to Maths as $i$ am good in it but $i$ want start my own music band as it is of my interest."

In one of the study done by Luke et.al (2015), it was concluded that many schools continuously strive to improve student achievement, and school counselors play a vital role in helping students to plan for success. The initiative emphasizes increasing support and resources to school counselors in helping to ensure that all students understand the requirements they need to complete during their education in preparation for college or a career after high school.

A lot more answers came up which suggested that parents have a lot of say in their career decisions and in many cases; it doesn't match with student's choice. One of the private school student of class $10^{\text {th }}$ stated -"I don't like sciences. I don't want to go to medical field at all. But since my aunt is a well known cardiologist, my mom wants me to become a doctor but $\mathrm{i}$ hate science. Now based on my percentage, $\mathrm{i}$ have been allotted science stream in $11^{\text {th }}$. I have to do it now anyways."

This statement clearly suggests that the child is least interested in sciences but still will take up the subject only to fulfil her mother's dream. Similar cases were reported amongst class $11^{\text {th }}$ students of private school. The government school respondents also reported similar factors affecting their career. The only difference reported by them and observed by the researcher as well was that the respondents of government school were not aware about the counselling services in their school. Therefore they could not say much about the importance of counselling services. Although they showed a desire to take such help but did not respond much openly. Private school students were more open about taking help from their school counsellor with respect to their career confusions and decisions.

Private school students appreciated the counselling services provided by their school. They reported that it is of great importance to them. The counsellor has helped them in clarifying their career related doubts a lot. Although, this study was bound by certain limitations; the majority of the participants were from a private school, the findings of this study cannot be generalized. Also, there were less female representatives as compared to males. Another limitation of this study is that our sample size is very small to conclude and generalize our findings for both the sectors of schools. Our sample for the study only included students from class $10^{\text {th }} \& 11^{\text {th }}$ and it did not represent the students of class $12^{\text {th }}$ due to which this study might have missed the variety and richness of responses which could have been possible if they could have been interviewed.

\section{CONCLUSION}

Choosing a career path might help the students set professional goals and develop a strategy for getting where they want to be. Part of choosing an appropriate career path involves making an honest self-evaluation of the talents, abilities and interests. While elements of that path may change over time due to choice or circumstance, having an overall professional objective with which to guide one will help one to make critical decisions with greater clarity.

Career selection is one of many important choices students will make in determining future plans. This decision will impact them throughout their lives. The essence of who the student is will revolve around what the student wants to do with their life-long work. Every student carries the unique history of their past and this determines how they view the world. That history created, in part by the student's environment, personality, and opportunity, will determine how students make career choices. It then follows that how the student perceives their environment, personality, and opportunity also will determine the career choices students make.

Thus, the present study helped us to probe such factors \& to become aware of certain aspects of career decision making process of the students. No major difference was found in the factors affecting the students of private school as compared to government school. Although, only private school students could talk about the importance of counselling \& its impact on career decision making since they were getting help from the school counsellor, which was missing in the government school.

\section{RECOMMENDATIONS}

There are certain recommendations as well which can be taken into consideration from this study. Children should be assisted from their young age for them to undergo necessary preparation to pursue the most appropriate career for them to pursue. Integrated Career Counselling must be sponsored in all the schools 
To Be or Not To Be: Exploring the Career Choices of Secondary and Senior Secondary School ..

including the government schools to ensure effective dissemination of relevant information to assist the students to avoid any mismatch between their interests and actual preferred courses of study. Parents should also be counselled to act as a support system for their children to assist them in career decision making process.

\section{REFERENCES}

[1]. Alger, A., \& Luke, M. (2015). The school counselor perspective: Preparing students to be college and career ready within a comprehensive school counseling program. The Practitioner Scholar: Journal of Counseling and Professional Psychology, 4(1).

[2]. Bandura, A., Barbaranelli, C., Caprara, G.V. and Pastorelli, C. (2001) Self-efficacy Beliefs as Shapers of Children's Aspirations and Career Trajectories. Child Development. 72: 187-206.

[3]. Betz, N. E., \& Hackett, G. (1987). Concept of agency in educational and career development. Journal of Counseling Psychology, 34, 299-308.

[4]. Ferry, N.M. (2006) Factors Influencing Career Choices of Adolescents and Young Adults in Rural Pennsylvania. Journal of Extension. 44 (3) 3RIB7:1-6

[5]. Sen, A. (2004). Elements of a theory of human rights. Philosophy \& Public Affairs, 32, 315-356.

Internet Reference-

[6]. http://www.delhi.gov.in/wps/wcm/connect/DOIT Education/education/home Retrieved January 21,2017 